\title{
Characteristics of High Gradient Insulators for Accelerator and High Power Flow Applications
}

Federal Manufacturing \& Technologies

J. M. Elizondo, M. L. Krogh, D. Smith,

D. Stoltz, and S. N. Wright, FM\&T, and

S. E. Sampayan, G. J. Caporaso, D. M. Sanders, R. D. Stoddard, and D. O. Trimble, Lawrence Livermore National Laboratory

KCP-613-5969

$$
\text { CONF-9706/13-- }
$$

Published July 1997

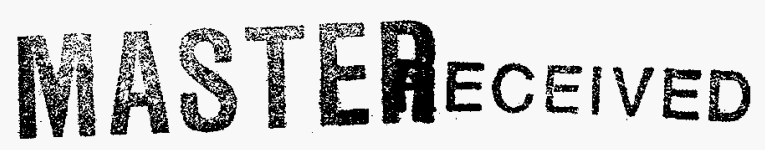

Approved for public release; distribution is unlimited.

DISTRIBUTION OF THIS DOCUMENT IS UNLIMTED

JUL $1^{4} 1997$

O STI

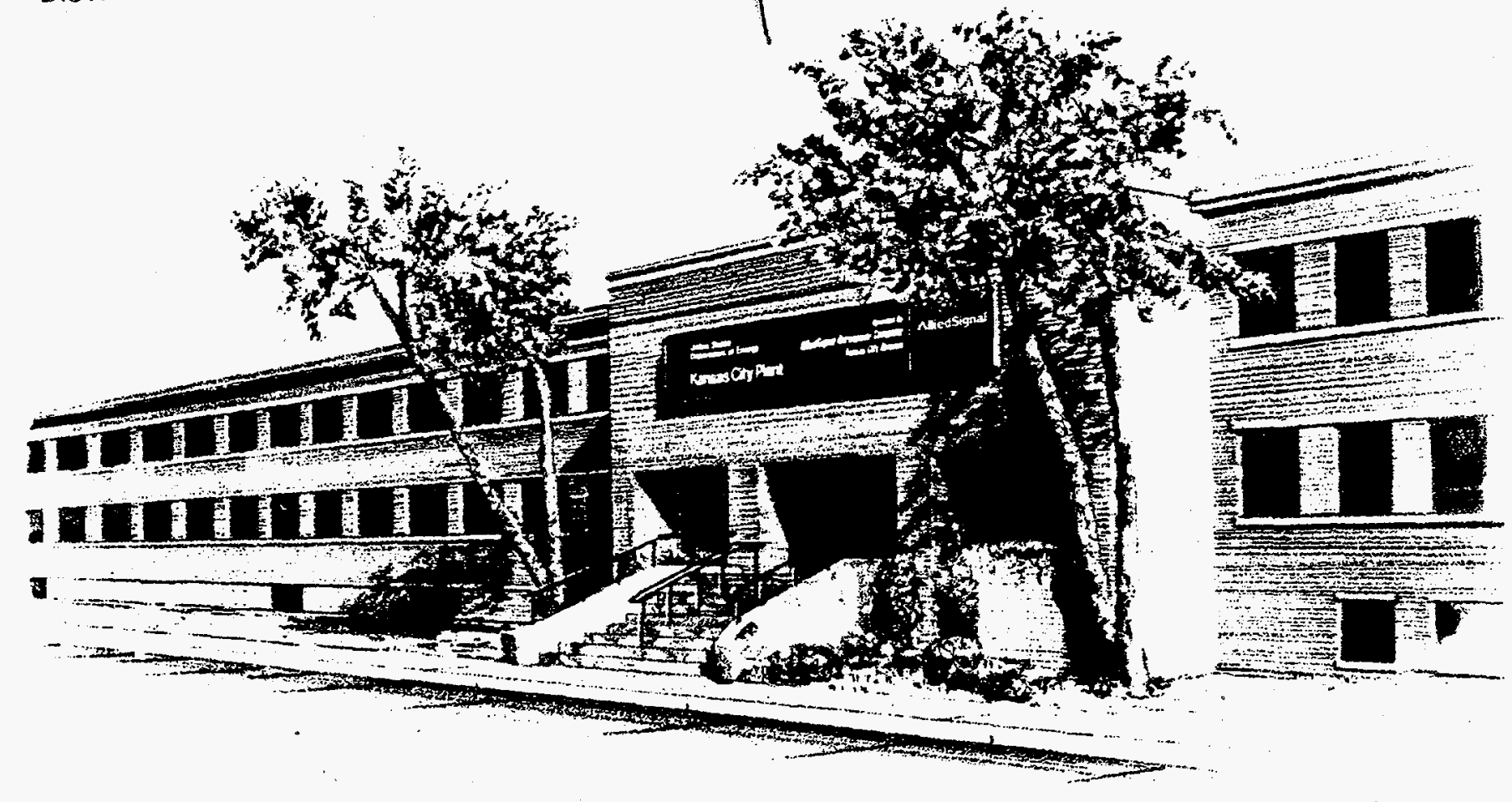

Prepared Under Contract Number DE-ACO4-76-DP00613 for the United States Department of Energy 


\section{DISCLAIMER}

Portions of this document may be illegible electronic image products. Images are produced from the best available original document. 


\section{DISCLAIMER}

This report was prepared as an account of work sponsored by an agency of the United States Government. Neither the United States Government nor any agency thereof, nor any of their employees, makes any warranty, express or implied, or assumes any legal liability or responsibility for the accuracy, completeness, or usefulness of any information, apparatus, product, or process disclosed, or represents that its use would not infringe privately owned rights. Reference herein to any specific commercial product, process, or service by trade names, trademark, manufacturer, or otherwise, does not necessarily constitute or imply its endorsement, recommendation, or favoring by the United States Government or any agency thereof. The views and opinions of authors expressed herein do not necessarily state or reflect those of the United States Government or any agency thereof.

Printed in the United States of America.

This report has been reproduced from the best available copy.

Available to DOE and DOE contractors from the Office of Scientific and Technical Information, P. O. Box 62, Oak Ridge, Tennessee 37831; prices available from (615) 576-8401, FTS 626-8401.

Available to the public from the National Technical Information Service, U. S. Department of Commerce, 5285 Port Royal Rd., Springfield, Virginia 22161.

Copyright $\odot 1997$ by AlliedSignal Inc. The Government is granted for itself and others acting on its behalf a paid-up, nonexclusive, irrevocable worldwide license in this data to reproduce, prepare derivative works, and perform publicly and display publicly.

A prime contractor with the United States Department of Energy under Contract Number DE-ACO4-76-DP00613.
AlliedSignal Inc. Federal Manufacturing \& Technologies P. O. Box 419159 Kansas City, Missouri 64141-6159 
KCP-613-5969

Distribution Category UC-706

Approved for public release; distribution is unlimited.

CHARACTERISTICS OF HIGH GRADIENT INSULATORS FOR ACCELERATOR AND HIGH POWER FLOW APPLICATIONS

J. M. Elizondo, M. L. Krogh, D. Smith,

D. Stoltz, and S. N. Wright, FM\&T, and

S. E. Sampayan, G. J. Caporaso, D. M. Sanders, R. D. Stoddard, and D. O. Trimble, Lawrence Livermore National Laboratory

Published July 1997

Paper submitted to $11^{\text {th }}$ IEEE International Pulsed Power Conference June 29 - July 2, 1997

Baltimore, MD 


\title{
CHARACTERISTICS OF HIGH GRADIENT INSULATORS FOR ACCELERATOR AND HIGH POWER FLOW APPLICATIONS
}

\author{
J. M. Elizondo, M. L. Krogh, D. Smith, D. Stoltz, and S. N. Wright \\ AlliedSignal Federal Manufacturing \& Technologies (FM\&T) ${ }^{*}$ \\ S. E. Sampayan, G. J. Caporaso, D. M. Sanders, R. D. Stoddard, \\ and D. O. Trimble \\ Lawrence Livermore National Laboratories
}

The high gradient insulator has been demonstrated to operate at levels comparable or better than special geometry or coated insulators. Some patented insulator configurations allow for sophisticated accelerator structures, high power flow interfaces, and microwave applications not previously possible. Sophisticated manufacturing techniques available at AlliedSignal FM\&T made this development possible. Bipolar and high power flow applications are specially suited for present insulator designs. The insulator shows a beneficial effect when used under RF fields or RF structures. These insulators can be designed, to a first approximation, from simple electron flight path equations. With a recently developed model of surface flashover physics we completed a set of design calculations that include effects such as layer density and dielectric/metal thickness. Experimental data, obtained in the last few years of development, is presented and reviewed. Several insulator fabrication characteristics, indicating critical design parameters, are also presented.

\section{INTRODUCTION}

The high gradient insulator was developed based on preliminary research that indicated a substantial increase to vacuum surface flashover voltage standoff obtained by stacking insulator layers [1]. It was also demonstrated that in the event of flashover current flowed through the metal edges "jumping" the dielectric surface, making it a choice candidate for high power flow applications [2]. Further research [3,4] demonstrated that properly designed physical discontinuities in the dielectric surface enhanced, or suppressed, vacuum surface flashover even in the presence of an electron beam. Initial calculations performed by the author, based in primary and secondary electron flight path, provided some explanation to the physics behind the insulator stack effectiveness. Design parameters were established based on the secondary electron range and flight elevation from the dielectric surface. The basic idea is to stop secondary electrons at the layer interface, thus preventing them from avalanching. This is done by placing a thin metal wafer with a larger outside diameter than the dielectric. The diameter difference between metal and dielectric is estimated from the maximum secondary electron flight elevation. The dielectric thickness is determined by the estimated secondary electron flight range.

These simple design indicators are based on the assumption that secondary electron emission dominates the onset and evolution of surface flashover. To obtain the maximum benefit from the insulator stacking other factors need to be included, factors such as dielectric vs metal thickness, dielectric minimum and maximum thickness, optimum number of layers, metal/dielectric optimum diameter differential. These effects were analyzed from a flashover physical model in which secondary electron avalanche is only a part of the process [5]. Effects such as electron impact ionization of desorbed material, photoelectron production, stimulated electron desorption, and electron injection to the subsurface need to be treated in parallel with the secondary electron avalanche. This paper describes the ongoing research in which dielectric stacking and manufacturing parameters have been studied. Test results from fused silica samples tested with bipolar and single polarity pulses are presented.

\footnotetext{
* Operated for the United States Department of Energy under Contract No. DE-ACO4-76-DP00613.
} 


\section{DESIGN SCALING RELATIONS}

The simple, dielectric stacking, scaling obtained from the secondary electron flight range and height are based on the assumption that the primary and secondary electron energies are known. These energies can be estimated within some upper and lower bound value. This yields an upper limit to the dielectric and metal dimensions with no regard to the relationship between local field enhancement, total number of layers, and layer density. As will be shown, a dielectric stack based only on the estimated secondary electron energy criteria will not perform to its full capability. The total number of layers, or layer density, and the relation between the dielectric and metal thickness affect the insulator performance. This was demonstrated during preliminary testing [2], which showed the strong effect between dielectric total thickness and metal placement.

To determine the effect of the layer density the approach is to calculate the total charge density that the surface (coupled through the layer capacitance) is capable of tolerating and compare it with the total charge that the system may produce. The idea is that material generated at the surface, from electron and photon stimulated processes, can be controlled with the proper dielectric-to-metal thickness ratio. In these calculations the system charge upper limit was assumed to be space charge dominated (Child-Langmuir). Figure 1 is the plot of the equation that relates the number of layers, layer thickness, field gradient, current through the gap, and stack total capacitance. The plot shows electron number density available in the vicinity of the insulator vs number of layers, with a specific thickness. The case shown in Figure 1 corresponds to $400 \mathrm{kV} / \mathrm{cm}$ field gradient and a start point of $50-\mu \mathrm{m}$ thick layers. This curve relates the maximum charge deposited or present at the dielectric surface (in between metal discs, since the flashover current seems to "skip" the dielectric surface and move through the metal edges. The charge trapped by the metals during conduction determines the insulator saturation point.

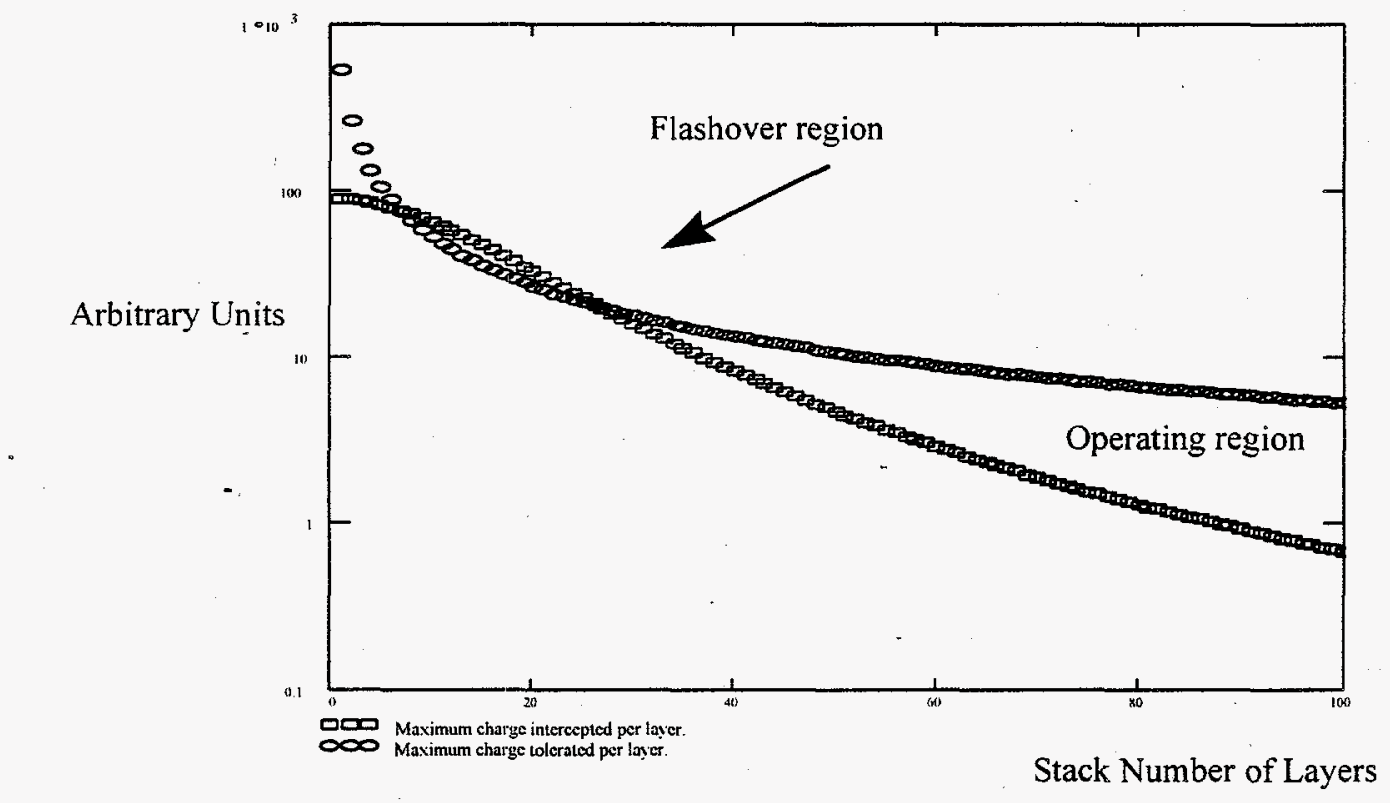

Figure 1. Characteristic Design Curve for Number of Layers and Total Charge (CV). The Operating Region is Clearly Identified.

The figure shows that there is a section of certain flashover followed by what we called the operating region. The curve also indicates that even if a single $50-\mu \mathrm{m}$ layer tolerates the full gradient (very thin dielectric wafers tolerate 
higher field gradients) as the number of layers is increased the curves cross over, defining a region of certain failure. As the number of layers is increased, the curves cross over again entering the proper operating region. Based on these calculations, curves for a specific insulator geometry are generated and the proper insulator layer density can be designed. There are some layer density dependencies not well understood; these dependencies are related to the streamer formation model of surface flashover. For instance, strong light emission has been observed before the onset of the breakdown flashover current. This light may come from the equivalent of a streamer precursor or from stimulated radiative transitions, in the material, by electron injection [6]. To suppress these effects, the metal-todielectric local interfaces, in the layered stack, are designed differently. The photo emission from the tip of the streamer may condition the surface so that there is enough ionized material to short-out the interlayer gap.

The next thing to analyze is the ratio of dielectric-to-metal thickness. This is accomplished by first looking at the local field enhancements, considering the metal and dielectric thickness and shape, and considering the shape of the metal edge (the shape of the dielectric is considered later). Figure 2 shows a typical design curve for the selection of the metal-to-dielectric ratio. As can be seen, for a given dielectric thickness there is an optimum metal thickness that keeps the local field enhancement to a minimum. The curves to the right correspond to two different dielectric thicknesses; the curves to the left correspond to metal thickness (top) and metal radius (bottom). Even though it is hard to define a radius at the metal working thickness, the curve shows the importance of the metal termination shape. A family of curves is generated following the initial dielectric thickness indicated by the layer density curve. The appropriate metal thickness is then selected in conjunction with that dielectric thickness.

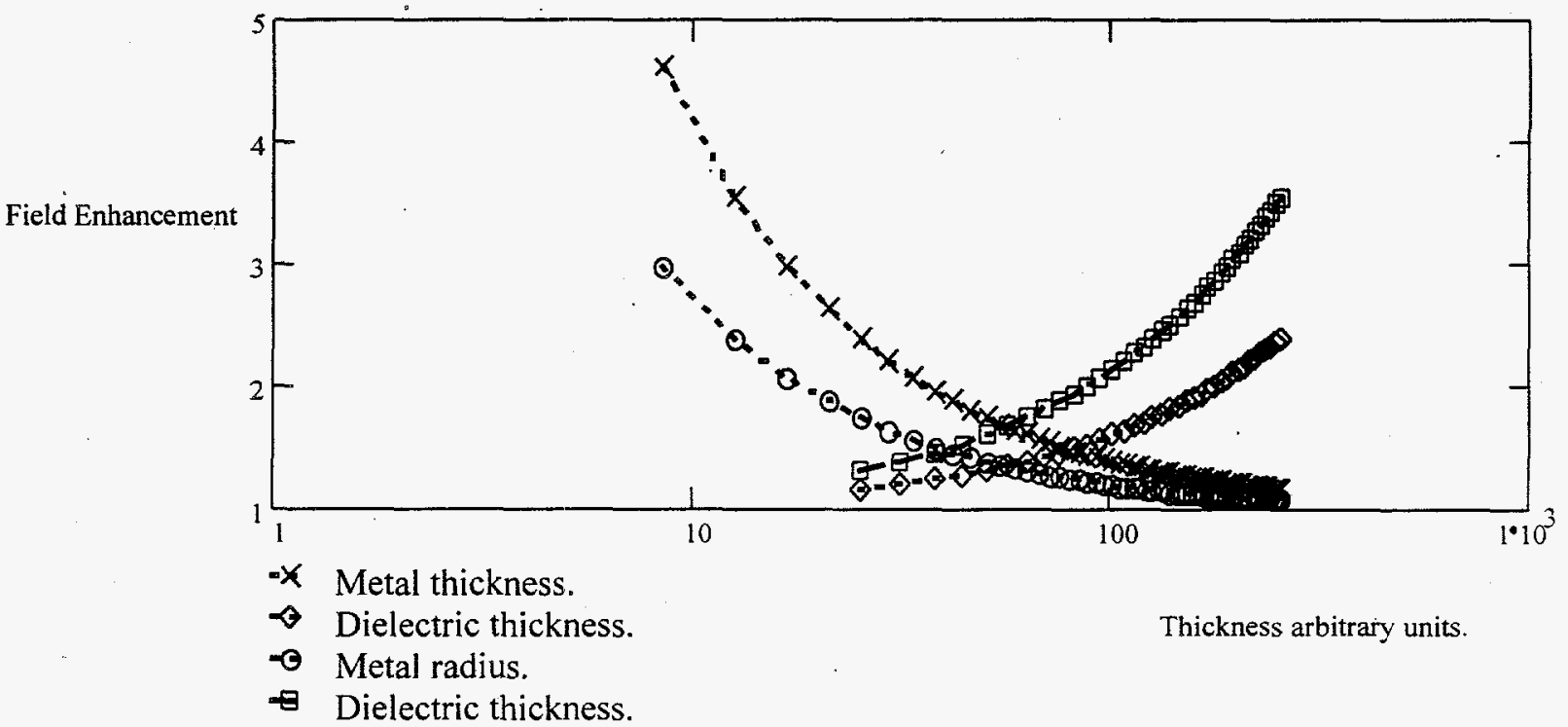

Figure 2. Characteristic Curve to Select Dielectric and Metal Thickness, Using Local Field Enhancement Criteria.

III. EXPERIMENTAL RESULTS/DATA 
Small sample testing (approximately $2.5 \mathrm{~cm}$ diameter by $0.5 \mathrm{~cm}$ thick) was performed in a turbo-molecular pumped, stainless steel chamber at approximately $10^{-6} \mathrm{~T}$. High voltage was developed with a $10 \mathrm{~J}$ "mini-Marx." The Marx developed a pulsed voltage of approximately 1 to $10 \mu$ s (base-to-base) and up to $250 \mathrm{kV}$ amplitude across the sample. Diagnostics consisted of an electric field sensor and a current viewing resistor. Failure of the insulator was determined by a prompt increase in Marx current and a prompt collapse in the voltage across the sample.

Several small sample insulators were fabricated by interleaving layers of $0.25 \mathrm{~mm}$ fused silica, formed by a sputtering technique and then bonding. Bond strength between the gold layer and substrate using this technique was measured to exceed $10 \mathrm{kpsi}$. To perform the breakdown experiments, the structure was slightly compressed between highly polished bare aluminum electrodes that establish the electric field for the tests.

After a short conditioning phase, we applied up to 150 to 200 shots to a given structure and attempted to determine if any damage to the structure occurred that significantly altered the breakdown characteristics. At these applied energies, we generally did not observe any degradation. These data were then reduced to reliability plots by determining the total number of successful shots over the total number of applied shots. In these data we define the electric field as the applied voltage divided by the total insulator length. We define reliability at a given electric field as the total number of successful shots over the total number of shots.

We observed flashover of the small samples at approximately $175 \mathrm{kV} / \mathrm{cm}$ for the fused silica substrates (Figure 3 ). The effect of pulse width from 1 to $10 \mu$ s on this breakdown threshold was well within the statistical nature of our data. The trend in conventional insulator technology for $0^{\circ}$-insulators indicates a threshold of approximately $50 \mathrm{kV} / \mathrm{cm}$. Thus, a net increase in the performance over conventional technology was a factor of approximately 3.5 .

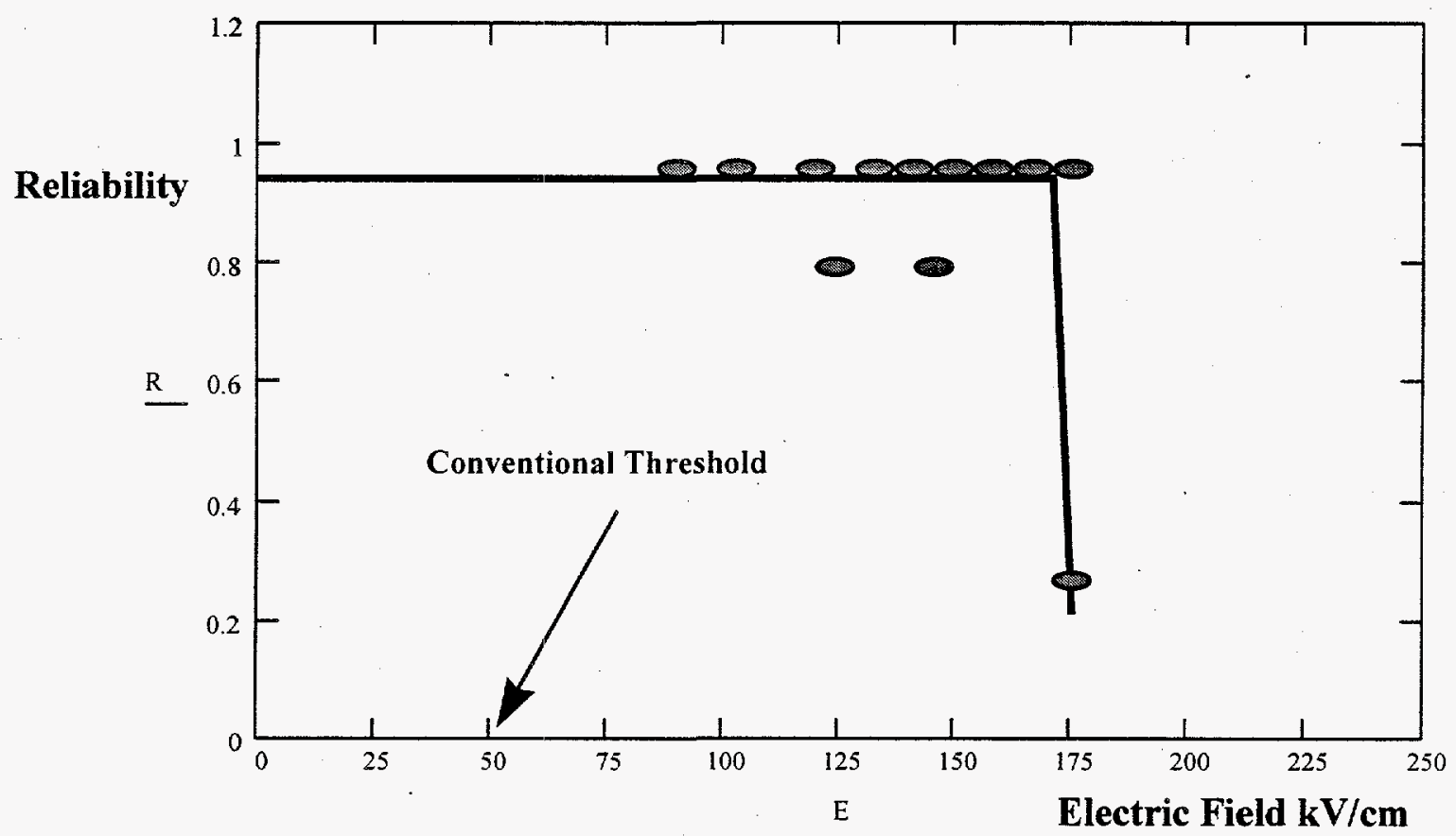

Figure 3.

A finish grinding operation was generally performed on the outside diameter. Since this process is time-consuming, an alternate fabrication means was pursued. To simplify fabrication, we attempted an ultrasonic machining process. Although it was possible to fabricate the part in a single operation, the surface was left slightly rougher. Comparison with these samples showed significantly more scatter and a slightly decreased breakdown threshold of $25 \%$. 
We have also begun testing these structures under bipolar stress. The applied pulses were generated by placing an inductor between the insulator and allowing the Marx generator to undergo undamped oscillation ( $\tau_{\mathrm{p}}=500 \mathrm{~ns}$ ). This technique would subject the insulator structures to approximately 10 fully reversing pulses. Results are shown in Figure 4. Comparison with previous data, scaled to area, shows a strong dependence on the insulator period. Increased performance over conventional technology [7] (Rexolite, $0^{\circ}$ ) was exceeded by a factor of 4 .

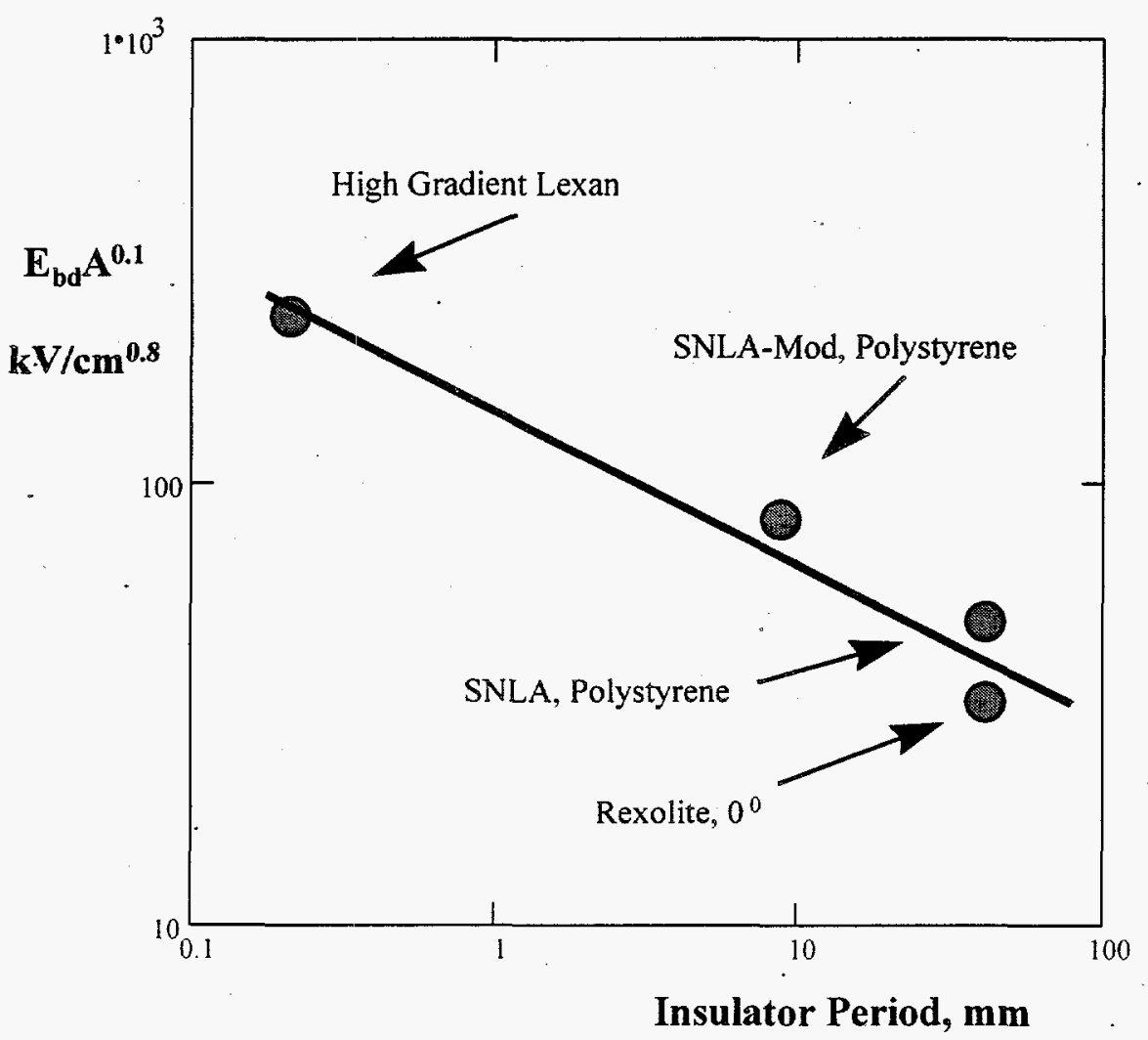

Figure 4.

\section{SUMMARY}

We are developing the high gradient insulator technology for accelerators and high power flow applications. We have demonstrated field gradients in excess of $150 \mathrm{kV} / \mathrm{cm}$ with ceramic and fused silica insulators, in a cylindrical shape. This value is 2 to 3 times that normally expected from ceramic and the best of glasses. The principle of operation is partly based on the fact that suppression of secondary electrons increases flashover standoff, and that 
thinner dielectric tolerates higher field gradients. This is an important development given that ceramics can be vacuum "baked" and that mechanical properties (compression) exceeds those of conventional polymers. Early high. gradient insulator development was done using a simple technique which combined a thermoset and a dielectric in a laminated stack. This technique was simple but limited the possible applications. New material development and sophisticated bonding techniques have made possible insulation stack structures for RF and ultra high vacuum applications. Ongoing research is focused on the development of new insulator structures, novel manufacturing techniques, and a detailed set of design and scaling tools.

\section{REFERENCES}

[1] J. M. Elizondo and A. Rodriguez, Proceedings of the 1992 15th International Symposium on Discharges and Electrical Insulation in Vacuum, Vde-Verlag Gmbh, Berlin, Germany, pp. 198-202.

[2] J. M. Elizondo, Proceedings of the $19939^{\text {th }}$ International Pulsed Power Conference, (IEEE), Albuquerque, N. M. , pp. 257-260.

[3] S. Sampayan, et. al., Proceedings of the 1995 Particle Accelerator Conference, (IEEE), New York, N.Y., pp. 1269-1271.

[4] S. Sampayan, et. al., Proceedings of the 1995 Particle Accelerator Conference, (IEEE), New York, N.Y., pp. 2123-2125.

[5] Elizondo, J. M., et. al., these proceedings.

[6] H. Kirkici, Proceedings of the 1996 16th International Symposium on Discharges and Electrical Insulation in Vacuum, Berkley, 1996.

[7] R. A. Anderson and W. K. Tucker, J. Appl. Phys., Vol 58(8), pp. 3346-3349. 